\title{
Activated release of hexanal and salicylaldehyde from imidazolidine precursors encapsulated in electrospun ethylcellulose-poly(ethylene oxide) fibers
}

\author{
Caihua Shi ${ }^{1} \cdot$ Apratim Jash $^{2} \cdot$ Loong-Tak Lim $^{1}$ (I)
}

Received: 31 August 2019 / Accepted: 12 February 2021 / Published online: 27 February 2021

(c) The Author(s) 2021 OPEN

\begin{abstract}
Hexanal and salicylaldehyde are naturally-occurring antimicrobial volatiles from edible plants known for their efficacy for post-harvest preservation of fruits and vegetables. Due to their volatility and susceptibility to oxidation, these volatiles must be encapsulated within a carrier to control their release, especially when applied in modified atmnosphere and active packaging applications. In this study, salicylaldehyde precursor (SP; 1,3-dibenzylethane-2-hydroxyphenyl imidazolidine) and hexanal precursor (HP) were synthetized through a Schiff base reaction between these aldehydes and $N, N^{\prime}$-dibenzylethane-1,2-diamine. The structure of SP was confirmed using nuclear magnetic resonance and attenuated total reflection-Fourier transform infrared (FTIR) spectroscopies. SP and HP, separately and in combinations, were encapsulated within ethylcellulose-poly(ethylene oxide) (EC-PEO) nonwoven membranes, using a free-surface electrospinning technique. Scanning electron microscopy showed that the morphology of the fibers varied substantially with SP and HP ratio. Specific interactions between SP and HP with the polymers were not detected from the FTIR spectroscopy analysis, suggesting that the precursors were mainly physically entrapped within the EC-PEO fiber matrix. Headspace gas chromatography showed that the release of hexanal and salicylaldehyde could be activated by contacting the precursorcontaining electrospun nonwoven with an acidified agarose gel containing $0.003-0.3 \mathrm{M}$ of citric acid. The delivery system can be promising for controlled release of hexanal and salicylaldehyde to extend the shelf-life of fruits and vegetables.
\end{abstract}

Keywords Salicylaldehyde · Hexanal · Imidazolidine precursor $\cdot$ Free surface electrospinning $\cdot$ Controlled release

\section{Introduction}

The World and Agriculture Organization estimated that approximately 1.3 billion tonnes of food intended for human consumption is wasted annually, among which, fruits and vegetables account for the greatest wastage (nearly $50 \%$ of the production) [1]. Deterioration of fruits and vegetables can take place during production, post-harvest, and distribution due to improper handling, thermal abuse, and microbial proliferation, leading to significant losses and potentially causing food-borne diseases $[2,3]$. To overcome these issues, cold storage and the use of chemical disinfectants (e.g., chlorine dioxide) are common at the industrial level $[4,5]$. However, cold distribution is expensive, which may not be available in certain regions [5]. Moreover, chemical disinfectants are not desirable from environment, public health, and consumer's perception standpoints [6-8].

\footnotetext{
Supplementary Information The online version of this article (https://doi.org/10.1007/s42452-021-04372-3) contains supplementary material, which is available to authorized users.
}

Loong-Tak Lim, Ilim@uoguelph.ca | ${ }^{1}$ Department of Food Science, University of Guelph, Guelph, ON N1G 2W1, Canada. ${ }^{2}$ Department of Food Science, Cornell University, Ithaca, NY 14850, USA. 
Hexanal is a six-carbon aliphatic aldehyde that produces grassy flavor in many fresh produces. It is produced in plant tissues through a lipoxygenase pathway [9]. As a naturally occurring volatile with generally-recognized-assafe status, hexanal is commonly used as a food flavoring agent [10]. Researchers have demonstrated that hexanal is an antimicrobial compound. Song et al. (2007) reported that the fungistatic effects of hexanal against Botrytis cinereal in raspberry and Monilinia fructicola in peach fruits at a vapor treatment concentration of $900 \mu \mathrm{L} \mathrm{L}-1$ for $24 \mathrm{~h}$ at $20^{\circ} \mathrm{C}[10]$. Bactericidal effects of hexanal vapor against Listeria monocytogenes were reported at $150 \mathrm{ppm}$ in package headspace for freshly-sliced apples at $20^{\circ} \mathrm{C}$ [11]. In addition to its antimicrobial properties, hexanal is also an inhibitor of phospholipase D-a cellular enzyme that catalyzes the hydrolysis of phospholipids in cell membranes. The phospholipase $D$ inhibition properties have been exploited for the preservation of fresh fruits and vegetables. For example, postharvest treatment of mango fruits by dipping them into a solution containing $0.02 \%(\mathrm{w} / \mathrm{w})$ of hexanal for 10 min resulted in reductions of ethylene production rate, oxidants content, and phospholipase $D$ activity as compared to the untreated fruits during 12 days of storage at $25^{\circ} \mathrm{C}$ and $60 \%$ relative humidity [12]. Cheema et al. evaluated the effects of hexanal $(0.005-0.02 \%, w / w)$ on sweet bell peppers. They observed significant delay in ripening and enhanced quality parameters (increased firmness, reduced water loss, lowered electrical conductivity) for the treated samples as compared to the untreated controls, during 21 days of storage. They also reported increased antioxidant enzyme activities for superoxide dismutase, catalase, glutathione reductase, and guaiacol peroxidase [13]. Other fruits that elicit delayed ripening and senescence responses to hexanal treatments include tomatoes [14], sweet cherries [15], and nectarines [16].

Salicylaldehyde is an aromatic aldehyde found naturally in buckwheat groats [17] and many other food products (e.g. grape, tomato, cinnamon, milk, coffee, tea). It is a flavoring agent [18], which also possesses antimicrobial properties effective against the development of Penicillium hirsutum, Staphylococcus aureus, Escherichia coli, Pseudomonas aeruginosa, Salmonella enteritidis, Candida albicans, and Aspergillus niger [19, 20]. Salicylaldehyde is known to react with amino acids, such as $\gamma$-aminobutyric acid, to generate Schiff base adduct which displayed bactericidal activities against $S$. aureus at $375 \mu \mathrm{g} \mathrm{mL}^{-1}$ of the broth medium [21]. Moreover, salicylaldehyde exhibits nematocidal properties against Meloidogyne incognita which causes infections in crop roots [22,23].

Although these aldehydes are useful for post-harvest fruit and vegetable preservation, their end-use applications can be challenging due to their volatility and susceptibility to oxidative degradation [24]. While encapsulating the volatile aldehydes within a polymer carrier can help address these issues, the encapsulation efficiency tends to be poor due to evaporative losses during the encapsulation process. Moreover, oxidative degradation of the encapsulated aldehydes can still occur during storage, albeit at a reduced rate as compared to the free counterparts. Another strategy is to convert the aldehyde into a meta-stable precursor, which can be activated under mild condition to release the original aldehyde. To this end, researchers have exploited $N, N^{\prime}$-substituted diamines to convert volatile aldehydes into their imidazolidine precursors, which can be hydrolysed readily in the presence of a mild acid, to trigger the release of the volatiles. For example, $N, N^{\prime}$-dibenzylethane-1,2-diamine has been used as a substrate for the synthesis of 1,3-dibenzylethane-2-pentyl imidazolidine and 1,3-dibenzylethane-2-phenyl imidazolidine, which are precursors for hexanal and benzylaldehyde, respectively $[25,26]$.

To facilitate the delivery of precursor compounds and control the release of bioactive volatiles during end-use applications, it is essential to develop an optimal carrier system. One carrier material that has attracted considerable research interest over the past decade are electrospun nonwovens made up of submicron fibers with high surface area-to-volume ratio. Typical electrospinning process involves pumping the spin dope polymer solution through a single- or multiple-needle spinneret connected to an electrically charged electrode. The electrostatic charge buildup on the surface of the solution overcomes its surface tension, causing it to eject towards an electrically grounded collector. As the polymer jet solidified and laid down on the target, a nonwoven membrane is obtained [27]. Although this setup is straightforward, there are substantial production challenges, including low throughput, blockage of the needle spinneret, instability of Taylor cone, and so on. To overcome these limitations, spinneret-less free surface electrospinning techniques have been developed, whereby a large number fiber jets are generated from continuous surfaces, such as wire [28-30], cylinder [31], porous tube [32], spin dope solution reservoir [33, 34], and so on. In the present study, a high throughput free surface electrospinning method conducive for large scale production was adapted to develop composite nonwoven carriers for salicylaldehyde and hexanal precursors. The resulting bioactive nonwovens are promising for active food packaging applications to deliver these naturally occurring antimicrobials for shelf-life extension of perishable products, such as fresh fruits and vegetables.

The objectives of this study are: (1) to synthetize salicylaldehyde precursor (SP) and hexanal precursor (HP), which are hydrolysable for triggered release of hexanal and salicylaldehyde vapors; (2) to encapsulate SP and HP in ethyl cellulose-poly(ethylene oxide) (EC-PEO) nonwovens 
using a free surface electrospinning technique; (3) to characterize the morphology of precursor-loaded nonwovens; (4) to study the release behaviours of hexanal and salicylaldehyde vapors from SP and HP, respectively, triggered by citric acid gels.

\section{Materials and methods}

\subsection{Materials}

Salicylaldehyde (reagent grade, 98\%), hexanal (98\%), EC (viscosity $22 \mathrm{cP}, 48 \%$ ethoxyl), PEO (molecular weight $300 \mathrm{kDa}$ ), and citric acid monohydrate (ACS grade, $\geq 99.0 \%$ ) were purchased from Sigma-Aldrich (Oakville, ON, Canada). $N, N^{\prime}$-dibenzylethane-1,2-diamine (97\% purity), 2-propanol (OPTIMA ${ }^{\text {TM }},>99.9 \%$ purity), ethyl acetate (Certified ACS grade, $>99.5 \%$ purity), $50 \mathrm{~mm}$ petri dishes, and agarose (molecular genetics grade) were procured from Fisher Scientific (Ottawa, ON, Canada). Anhydrous ethanol was supplied by Commercial Alcohol (Brampton, ON, Canada).

\subsection{Preparation of SP and HP}

SP and HP were synthetized according to Jash and Lim [25]. Briefly, salicylaldehyde or hexanal was dispersed in anhydrous ethanol, followed by the addition of an equimolar of $N, N^{\prime}$-dibenzylethane-1,2-diamine. The mixture was stirred at $22 \pm 2{ }^{\circ} \mathrm{C}$ for $2 \mathrm{~h}$ to form a uniform solution. The ethanol was then evaporated for $24 \mathrm{~h}$ to produce the precursor powders. Precursor stock solutions were prepared by dissolving SP and HP separately into ethyl acetate at 1:5 (w:w) ratio. To investigate the effect of SP and HP blend ratio on electrospinning, precursor solutions at different weight blend ratios, i.e., 100:0, 75:25, 50:50, 25:75, and 0:100 SP:HP were prepared, coded as 100SP0HP, 75SP25HP, 50SP50HP, 25SP75HP, and 0SP100HP, respectively.

\subsection{Preparation of spin dope solutions for electrospinning}

EC and PEO were electrospun into nonwoven carriers for the SP and HP synthetized in Sect. 2.2. EC was chosen for this research because it is environmentally sustainable, biodegradable, non-toxic, and has great film-forming properties [35-38]. A trace amount of PEO was incorporated as a process aid to stabilize the spin dope solution during electrospinning, by introducing charge-countering and polymer chain-chain entanglement effects [39-43]. The spin dope solution was prepared by dissolving $10 \%(\mathrm{w} / \mathrm{w})$ of EC and 0.1\% (w/w) of PEO in 99:1 (w:w) 2-propanol: $\mathrm{H}_{2} \mathrm{O}$ blend solvent. The mixture was heated to $70^{\circ} \mathrm{C}$ and stirred for $1 \mathrm{~h}$ to obtain a homogeneous solution, followed by cooling to room temperature before electrospinning. Pristine $10 \%(\mathrm{w} / \mathrm{w})$ EC solution was prepared similarly except that the PEO was omitted. The precursor-loaded spin dope solutions were prepared by mixing the polymer solutions with the precursor stock solutions (Sect. 2.2) at 1:1 weight ratio and stirred for $30 \mathrm{~min}$.

\subsection{Electrospinning}

EC, EC-PEO, and precursor-loaded electrospun fibers were prepared using a free surface electrospinning equipment (NanoSpider ${ }^{\mathrm{TM}}$ NS LAB, Elmarco, Svarovska, Liberec, Czech Republic). The spin dope solution $(10 \mathrm{~mL})$ was loaded onto the reservoir equipped with a small orifice $(0.7 \mathrm{~mm}$ diameter), through which a stainless-steel spinning electrode wire $(0.2 \mathrm{~mm}$ diameter) passed through in a concentric manner. The wire was connected to the positive electrode of a DC power supply, set at $40 \mathrm{kV}$. As the carriage of the reservoir shuttled back-and-forth at a speed of $90 \mathrm{~mm} / \mathrm{s}$, the spin dope solution was evenly deposited on the surface of the electrode wire. The spin dope was electrified by the applied voltage, resulting in the formation of many jets emitting towards an electrically grounded collector wire electrode. The jets were laid as nonwovens on a cellulosebased collector, positioned at $240 \mathrm{~mm}$ from the spinning electrode wire (Fig. 1).

\subsection{Nuclear magnetic resonance (NMR) and Infrared analyses of SP}

The molecular structure of SP was determined using ${ }^{1} \mathrm{H}$ and ${ }^{13} \mathrm{C}$ NMR spectroscopies. The precursor powders (50 mg) were mixed with $400 \mu \mathrm{L}$ of chloroform-d in a $5-\mathrm{mm}$ NMR tube. The NMR spectra were obtained by Bruker AVANCE $600 \mathrm{MHz}$ (14.1 T) NMR spectrometer (Bruker Corp., Billerica, MA, USA), and analyzed by TopSpinTM software (version TS3.5p16, Bruker Corp., Billerica, MA, USA).

Infrared spectra of SP, salicylaldehyde, and $N, N^{\prime}$-dibenzylethane-1,2-diamine, were analyzed by using a Fourier transform infrared (FTIR) spectrometer (IRPrestige 21, Shimazu Corp., Kyoto, Japan) equipped with an attenuated total reflection (ATR) accessory (Pike Technologies, Madison, WI, USA). Samples were scanned 40 times between 600 and $4000 \mathrm{~cm}^{-1}$ at $4 \mathrm{~cm}^{-1}$ resolution. IR Solution software (Shimazu Corp., Kyoto, Japan) was used to analyse the FTIR spectra. To study the interaction between polymer blend and the precursor compounds, spectra of the pristine EC-PEO and precursor-loaded electrospun nonwovens were also obtained. Three locations were selected from the electrospun samples for analysis. 


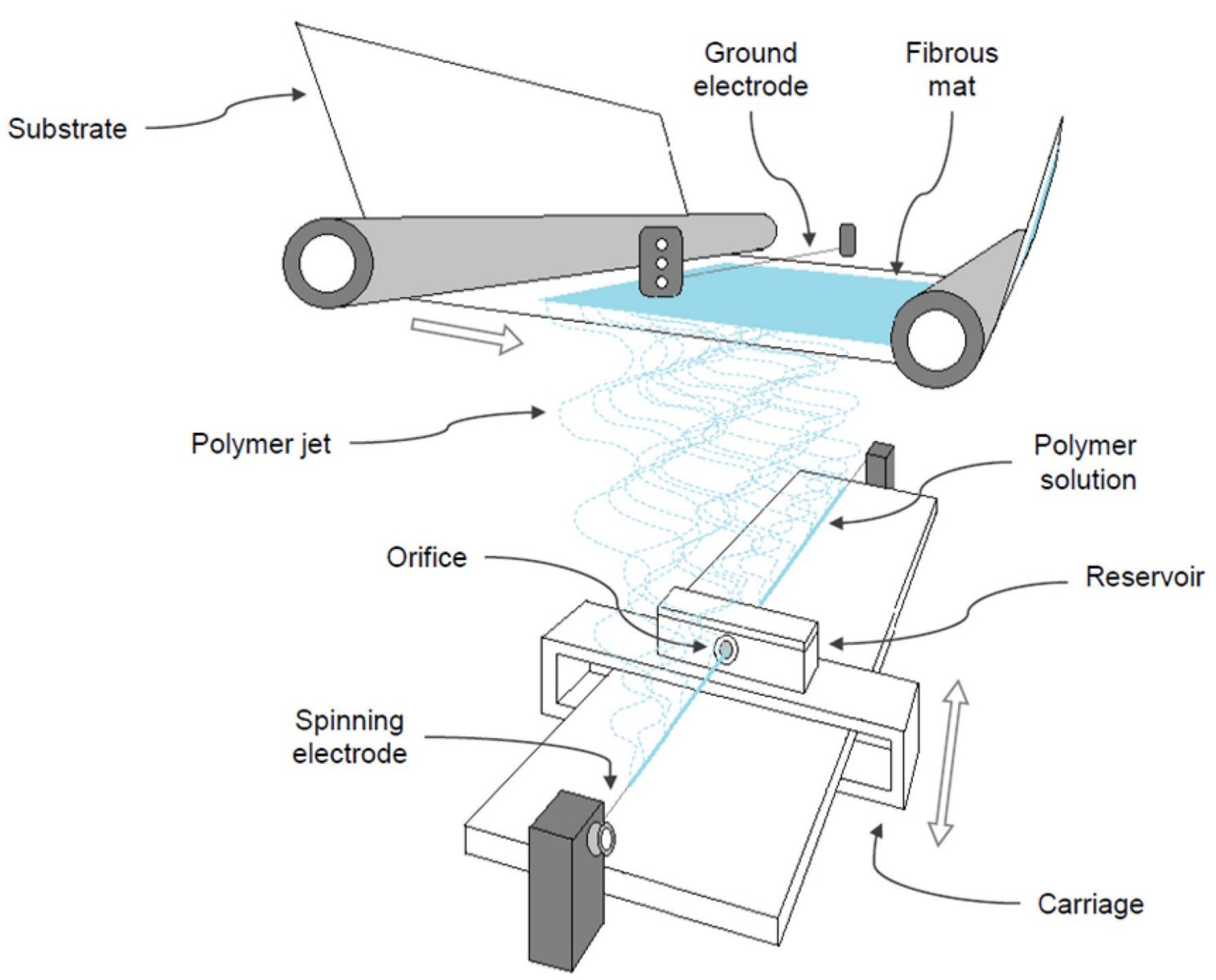

Fig. 1 Schematic perspective view of the equipment for free surface electrospinning. The spin dope solution was evenly deposited on the surface of the spinning electrode, as the carriage shuttled back-and-forth along the wire. The polymer jets emitting from the

\subsection{Microstructural analysis of electrospun fibers}

The morphology of electrospun carriers were examined using scanning electron microscopy (SEM; Quanta FEG 250, FEl Company, Hillsboro, OR, USA). Nonwoven specimens, randomly selected from three different locations, were placed on metal stubs attached with double-adhesive carbon tape, followed by gold-coating in a sputter coater (Desk V TSC, Denton Vacuum, Moorestown, NJ, USA). Sample analysis was conducted at an accelerating voltage of $10 \mathrm{kV}$. The distribution of fiber diameter was evaluated with 210 measurements using an image processing software (Image-Pro Premier 9.2, Media Cybernetics Inc., Rockville, MD, USA).

\subsection{Triggered release of precursors from electrospun nonwovens}

The release behaviours of salicylaldehyde and hexanal from the precursor-loaded EC-PEO nonwoven (50SP50HP) wire electrode deposited on a cellulose-based substrate, as electrospun nonwoven fibrous mat, which was cut into size for further analysis

were evaluated. The releases of these aldehydes were triggered by contacting the nonwoven with acidified agarose gels. The acidic gels were prepared by adding agarose into water at $1.5 \%(\mathrm{w} / \mathrm{w})$ polymer concentration, heated and stirred to form a homogeneous solution. The agarose solution was cooled down to $50^{\circ} \mathrm{C}$, followed by the addition of citric acid monohydrate $(0.003,0.03$, and $0.3 \mathrm{M}$ citric acid). An aliquot of $8 \mathrm{~mL}$ of the citric acid-agarose solution was transferred to $50 \mathrm{~mm}$ petri dishes and cooled to ambient temperature to solidify the agarose gels. The gels were stored at $4{ }^{\circ} \mathrm{C}$ until use.

A gas chromatograph (GC 6890, Agilent Technologies Inc., Santa Clara, CA, USA) equipped with a flame ionization detector (FID) was used to study the release behaviours of salicylaldehyde and hexanal. A piece of electrospun specimen ( $15 \mathrm{mg}$ ) was trimmed and positioned at the center of the acidified agarose gel. Immediately, the test sample was placed and sealed in a hermetic $960 \mathrm{~mL}$ glass jar with lid equipped with a septum. The headspace gas was extracted through the septum

\section{SN Applied Sciences}


automatically using a custom-built headspace sampling system $[44,45]$ at $15 \mathrm{~min}$ intervals for $6.5 \mathrm{~h}$. Test temperature was maintained at $20 \pm 0.5^{\circ} \mathrm{C}$ using an environmental chamber (MLR-350H, Sanyo Corp., Osaka, Japan). The headspace gas was extracted with the aid of a vacuum pump, stream selection valve, and gas sampling valve actuated by a controller (SRI Instruments, Las Vegas, USA). Nitrogen carrier gas $\left(30 \mathrm{~mL} \mathrm{~min}^{-1}\right.$ ) was used to purge the gas sample into a capillary column and finally to the FID detector. Hydrogen and compressed air flow rates to the FID were 50 and $200 \mathrm{~mL} \mathrm{~min}^{-1}$, respectively. Temperature profile of the oven was $95^{\circ} \mathrm{C}$ for $2.3 \mathrm{~min}$, ramped to $135^{\circ} \mathrm{C}$ at $80^{\circ} \mathrm{C} \mathrm{min}{ }^{-1}$ for $0.5 \mathrm{~min}$, and then held at $135^{\circ} \mathrm{C}$ for $2.2 \mathrm{~min}$. Results were analyzed by using a chromatography software (Peak454-64bitWin10, SRI Instruments, CA, USA). Calibration curves were prepared by analyzing known weight of pure hexanal and salicylaldehyde, respectively.

The amount of hexanal and salicylaldehyde at any sampling point $\left(\mathrm{M}_{\mathrm{c}}\right)$ was calculated by:

$M_{r}=C_{r} \times V_{b}$

$M_{l}=\left(C_{r-1} \times V_{e}\right)+M_{1-1}$

$M_{c}=M_{r}+M_{1}$

where $C_{r}$ represents the concentration of target aldehyde determined by the reference curve at the sampling point; $V_{b}$ is the volume of the glass jar; $C_{r-1}$ is the concentration of the previous sampling point; $\mathrm{V}_{\mathrm{e}}$ is the extracted volume of headspace gas; and $M_{1-1}$ is the accumulated mass loss from all the previous sampling points.

\subsection{Data analysis}

One-way ANOVA and Tukey's HSD test were performed using R software (Version 3.5.0., R Foundation for Statistical Computing, Vienna, Austria) to determine differences among treatments at a $95 \%$ confidence interval.

\section{Results and discussions}

\subsection{NMR analysis of SP}

The reaction of the aldehyde group of salicylaldehyde with the two secondary amino groups of $N, N^{\prime}$-dibenzylethane-1,2-diamine formed 1,3-dibenzylethane-2-hydroxyphenyl imidazolidine, which is the precursor of the aldehyde (Fig. 2). The regeneration of salicylaldehyde can be achieved by acid-catalyzed hydrolysis of the precursor. Similar reversible reactions have been reported by Morinaga et al. [46] and Buchs(née Levrand) et al. [47] for other imidazolidines.

The molecular structure of the synthesized SP was confirmed by ${ }^{1} \mathrm{H}$ NMR and ${ }^{13} \mathrm{C}$ NMR (Fig. $3 a$ and $b$, respectively) analyses, showing the presence of the formation of heterocyclic structure, while the benzene rings from substituted diamine and the aromatic hydroxyl group of salicylaldehyde remained unchanged. The peak assignments for ${ }^{1} \mathrm{H}$ NMR $(\mathrm{CDCl} 3,600 \mathrm{MHz}, \delta$ in ppm) analysis are as follows: $11.01(1 \mathrm{H}, \mathrm{Ph}-\mathrm{OH}) ; 7.29-6.80(14 \mathrm{H}$, $\mathrm{Ph}-\mathrm{H}) ; 3.97(\mathrm{~s}, 1 \mathrm{H},-\mathrm{N}-\mathrm{CH}-\mathrm{N}-)$; $3.95(\mathrm{~d}, \mathrm{~J}=13.84 \mathrm{~Hz}, 2 \mathrm{H}$, $-\mathrm{Ph}-\mathrm{CH}_{2}-\mathrm{N}-$ ); 3.26 (d, J = $12.88 \mathrm{~Hz}, 2 \mathrm{H},-\mathrm{Ph}-\mathrm{CH}_{2}-\mathrm{N}-$ ); 3.13-3.05 (m, 2H, $-\mathrm{N}-\mathrm{CH}_{2}-\mathrm{CH}_{2}-\mathrm{N}-$ or $\left.-\mathrm{N}-\mathrm{CH}_{2}-\mathrm{CH}_{2}-\mathrm{N}-\right)$; 2.55-2.47 (m, $2 \mathrm{H},-\mathrm{N}-\mathrm{CH}_{2}-\mathrm{CH}_{2}-\mathrm{N}-$ or $\left.-\mathrm{N}-\mathrm{CH}_{2}-\mathrm{CH}_{2}-\mathrm{N}-\right)$. The peak assignments for ${ }^{13} \mathrm{C}$ NMR $(\mathrm{CDCl} 3,600 \mathrm{MHz}$,

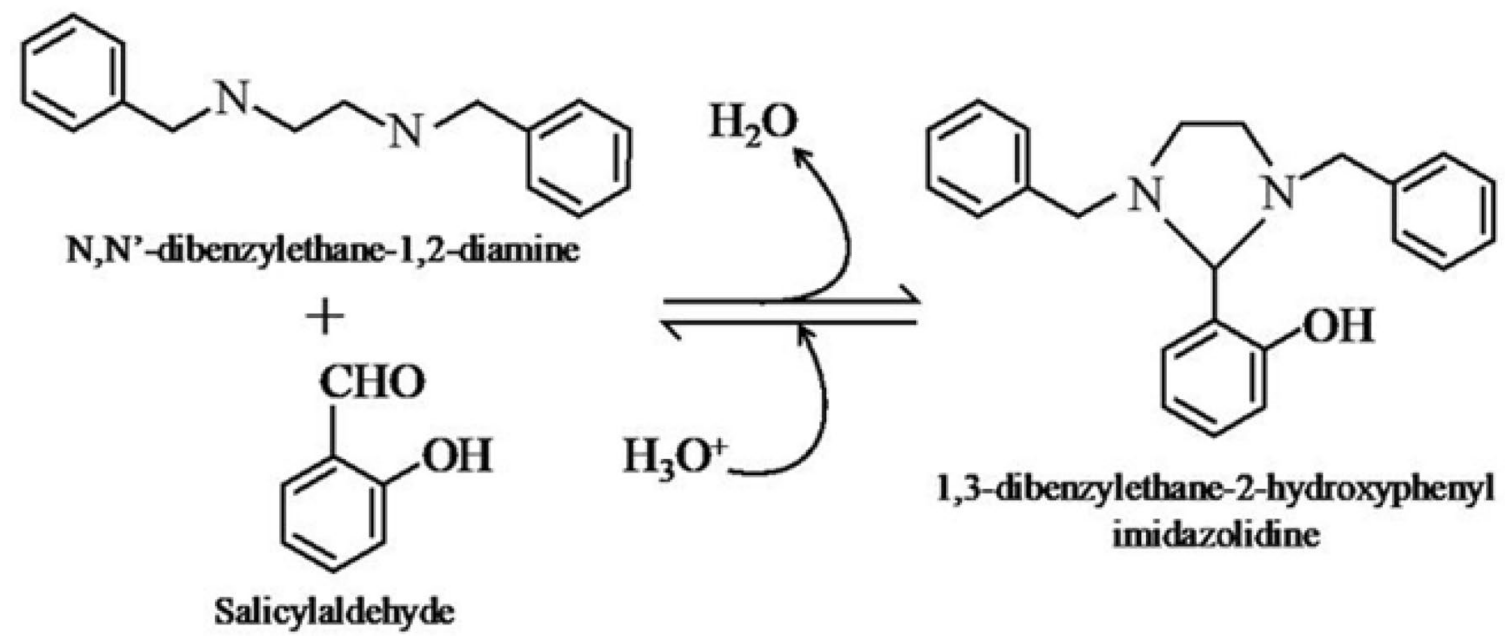

Fig. 2 Formation of 1,3-dibenzylethane-2-hydroxyphenyl imidazolidine (salicylaldehyde precursor) by the reaction of $N, N^{\prime}$-dibenzylethane1,2-diamine with salicylaldehyde. Acidcatalyzed hydrolysis of the precursor resulted in the release of salicylaldehyde 
(a)<smiles>CC1CN(Cc2ccccc2)C(c2ccccc2O)N1Cc1ccccc1</smiles>

${ }^{1} \mathrm{H} \mathrm{NMR}$

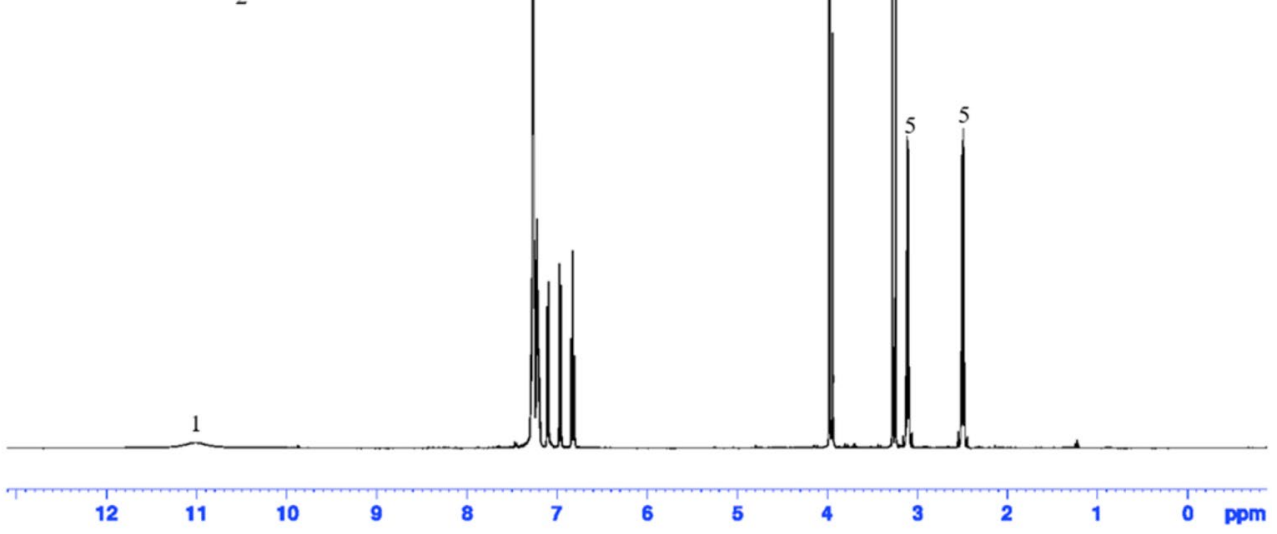

(b)

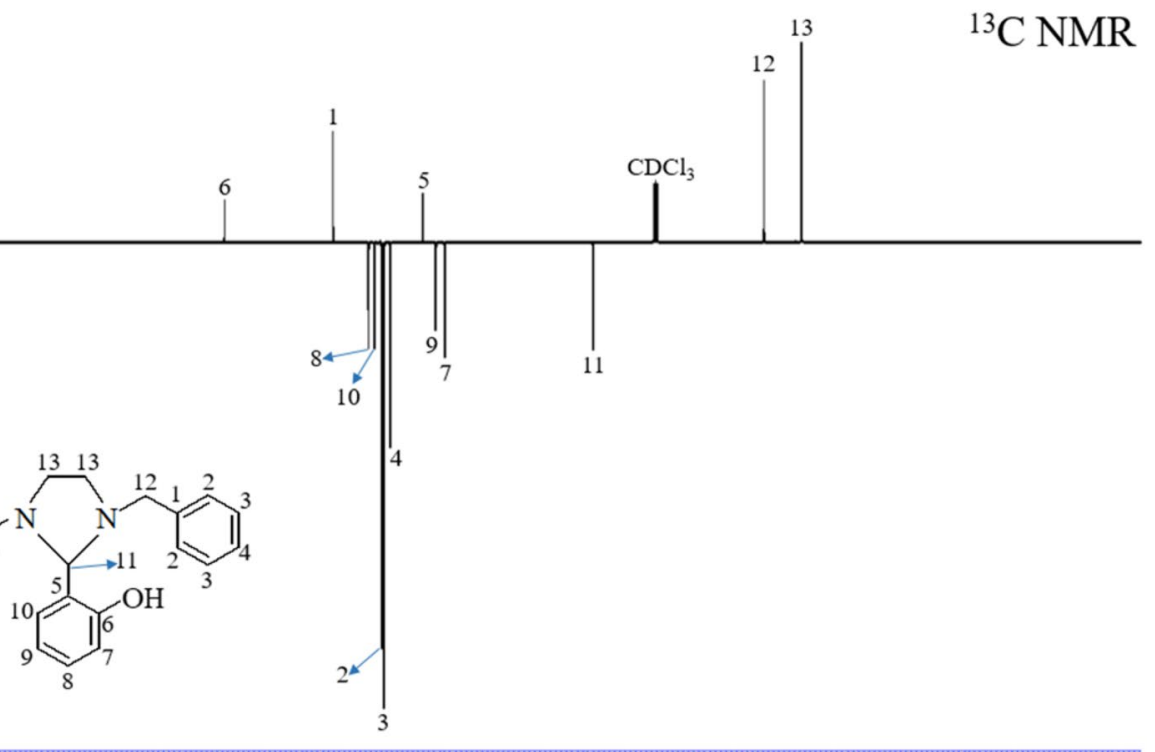

$\begin{array}{llllllllllllllllllllllll}220 & 210 & 200 & 190 & 180 & 170 & 160 & 150 & 140 & 130 & 120 & 110 & 100 & 90 & 80 & 70 & 60 & 50 & 40 & 30 & 20 & 10 & 0 & \mathrm{ppm}\end{array}$

Fig. 3 a ${ }^{1} \mathrm{H}$ NMR and $\mathbf{b}{ }^{13} \mathrm{C}$ NMR spectra of 1,3-dibenzylethane-2-hydroxyphenyl imidazolidine

$\delta$ in ppm) analysis are: $138.07\left(-\mathrm{CH}_{2}-\mathrm{Ph}-\mathrm{C}\left(1^{\prime}\right)\right)$; $128.88\left(-\mathrm{CH}_{2}-\mathrm{Ph}-\mathrm{CH}\left(2^{\prime}\right)\right.$ or $\left.-\mathrm{CH}_{2}-\mathrm{Ph}-\mathrm{CH}\left(3^{\prime}\right)\right)$; $128.47\left(-\mathrm{CH}_{2}-\mathrm{Ph}-\mathrm{CH}\left(3^{\prime}\right)\right.$ or $\left.-\mathrm{CH}_{2}-\mathrm{Ph}-\mathrm{CH}\left(2^{\prime}\right)\right) ; 127.31$ $\left(-\mathrm{CH}_{2}-\mathrm{Ph}-\mathrm{CH}\left(4^{\prime}\right)\right) ; 121.10\left(\mathrm{CH}-\mathrm{Ph}-\mathrm{C}\left(5^{\prime}\right)\right) ; 158.53$ $\left(\mathrm{CH}-\mathrm{Ph}-\mathrm{C}-\mathrm{OH}\left(6^{\prime}\right)\right) ; 117.03\left(\mathrm{CH}-\mathrm{Ph}-\mathrm{CH}\left(7^{\prime}\right)\right) ; 131.36$ $\left(\mathrm{CH}-\mathrm{Ph}-\mathrm{CH}\left(8^{\prime}\right)\right) ; 118.66\left(\mathrm{CH}-\mathrm{Ph}-\mathrm{CH}\left(9^{\prime}\right)\right) ; 130.29$ $\left(\mathrm{CH}-\mathrm{Ph}-\mathrm{CH}\left(10^{\prime}\right)\right) ; 89.03\left(\mathrm{~N}-\mathrm{CH}-\mathrm{N}\left(11^{\prime}\right)\right) ; 56.74$ $\left(\mathrm{Ph}-\mathrm{CH}_{2}-\mathrm{N}\left(12^{\prime}\right)\right) ; 49.66\left(\mathrm{~N}-\mathrm{CH}_{2}-\mathrm{CH}_{2}-\mathrm{N}\left(13^{\prime}\right)\right)$.

\subsection{ATR-FTIR analysis}

The FTIR spectrum (Fig. 4) for salicylaldehyde showed an absorbance band at $1660 \mathrm{~cm}^{-1}$ due to $C=O$ stretching of the aldehyde group [48]. Fermi doublets between 2850 and $2700 \mathrm{~cm}^{-1}$ were assigned to the aldehyde $\mathrm{C}-\mathrm{H}$ stretching [49]. The phenolic $\mathrm{C}-\mathrm{O}$ stretching was responsible for the band at $1273 \mathrm{~cm}^{-1}$, while the broad band 


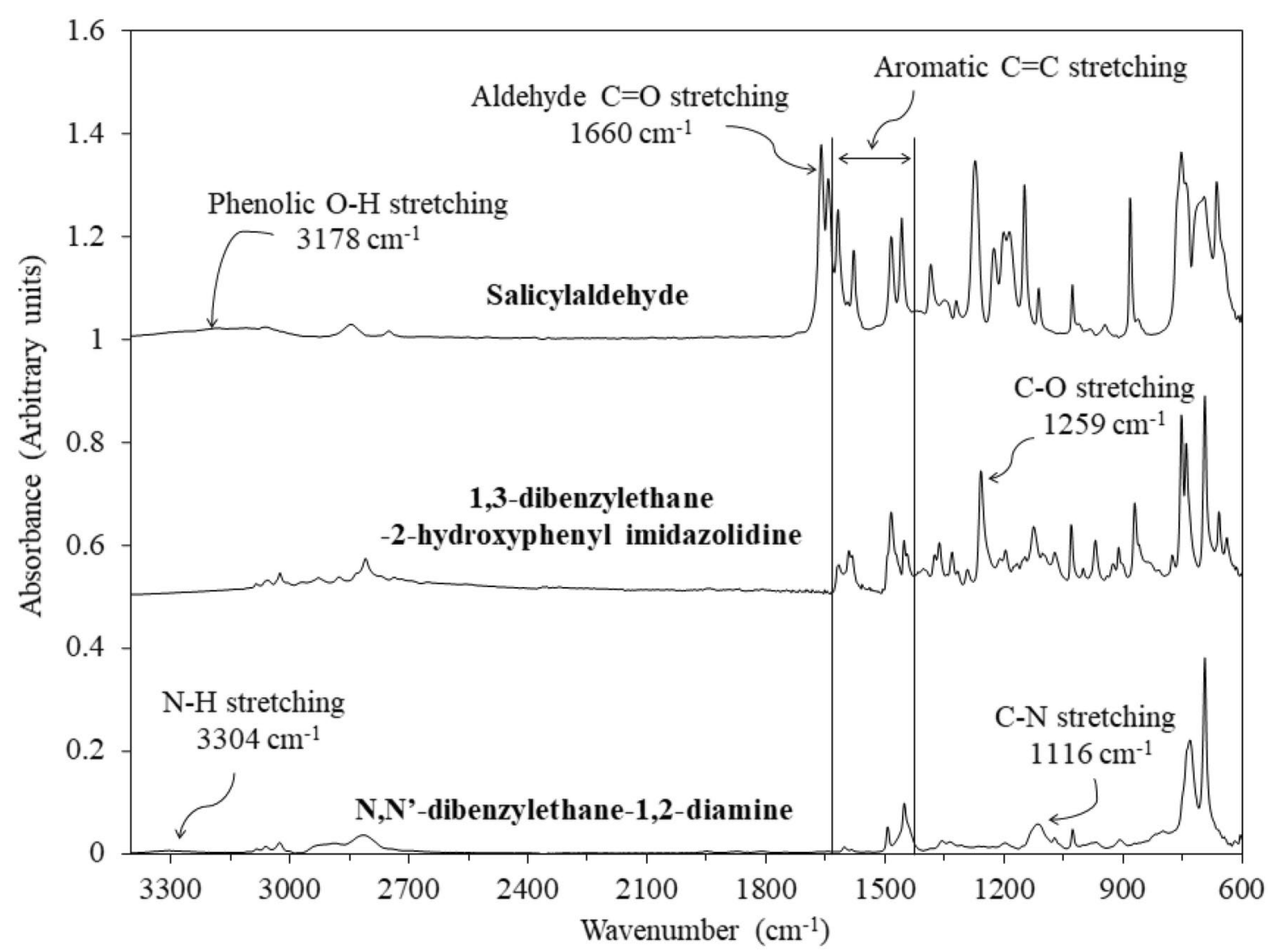

Fig. 4 Comparisons of ATR-FTIR spectra of salicylaldehyde, 1,3-dibenzylethane-2-hydroxyphenyl imidazolidine, and N, $N$ '-dibenzylethane1,2-diamine

around $3178 \mathrm{~cm}^{-1}$ could be attributed to the phenolic $\mathrm{O}-\mathrm{H}$ stretching. Absorbance bands at 1618, 1595, 1579, and $1485 \mathrm{~cm}^{-1}$ were due to the $\mathrm{C}=\mathrm{C}$ stretching of the orthodisubstituted benzene ring of salicylaldehyde. The strong band at $754 \mathrm{~cm}^{-1}$ was attributed to the out-of-plane $\mathrm{C}-\mathrm{H}$ bending. The spectrum of $N, N^{\prime}$-dibenzylethane-1,2-diamine showed a band at $1116 \mathrm{~cm}^{-1}$ which was related to the $\mathrm{C}-\mathrm{N}$ stretching of the secondary amine group. A weak band at $3304 \mathrm{~cm}^{-1}$ was due to the $\mathrm{N}-\mathrm{H}$ stretching. The mono-substituted benzene $\mathrm{C}=\mathrm{C}$ stretching gave rise to the absorbance bands at 1603,1492 , and $1452 \mathrm{~cm}^{-1}$. The bands at 752 and $694 \mathrm{~cm}^{-1}$ were due to the aromatic out-of-plane $\mathrm{C}-\mathrm{H}$ bending. For $\mathrm{SP}$, the characteristic $\mathrm{C}=\mathrm{O}$ stretching of aldehyde was not observed, indicating the absence of salicylaldehyde in the product. The absorbance of the phenolic $\mathrm{C}-\mathrm{O}$ stretching and the $\mathrm{C}-\mathrm{N}$ stretching from the secondary amine were shifted to lower frequencies (1259 and $1103 \mathrm{~cm}^{-1}$, respectively) as compared with the substrate compounds, as a result of the condensation reaction. On the other hand, no significant changes were detected among absorbance bands for the aromatic $\mathrm{C}=\mathrm{C}$ stretching and the out-of-plane $\mathrm{C}-\mathrm{H}$ bending, suggesting that benzene rings of salicylaldehyde and diamine remained unchanged after the formation of SP.

In Fig. 5, the absorbance band at $1055 \mathrm{~cm}^{-1}$ for the EC-PEO nonwoven was due to $\mathrm{C}-\mathrm{O}-\mathrm{C}$ stretching of EC [25]. Bands between 2700 and $3000 \mathrm{~cm}^{-1}$ were related to symmetric and asymmetric $\mathrm{C}-\mathrm{H}$ stretching within alkane groups. Precursor-loaded nonwovens exhibited similar spectral features, although the $\mathrm{C}-\mathrm{N}$ stretching of the imidazolidine precursor was evident as an absorbance band at $1101 \mathrm{~cm}^{-1}$. Absorbance bands at 1602, 1494, and $1452 \mathrm{~cm}^{-1}$ could be attributed to the mono-substituted benzene $\mathrm{C}=\mathrm{C}$ stretching from the diamine, while the aromatic out-of-plane $\mathrm{C}-\mathrm{H}$ bending vibrations appeared at 734 and $698 \mathrm{~cm}^{-1}$. The intensity of the $\mathrm{C}-\mathrm{O}$ absorbance bands altered with the SP:HP ratio; a reduction in intensity was observed as SP deceased in the electrospun fibers, with concomitant decreases in absorbance for aromatic $C=C$ stretching $\left(1618,1593\right.$, and $\left.1485 \mathrm{~cm}^{-1}\right)$ of ortho-disubstituted benzene ring and out-of-plane $\mathrm{C}-\mathrm{H}$ bending $\left(754 \mathrm{~cm}^{-1}\right)$. No specific interaction was detected between the polymers and the precursors, suggesting that SP and HP were mainly physically entrapped within the fiber matrix. 


\subsection{SEM microstructural analysis of electrospun fibers}

SEM analysis showed that the EC solution produced irregular particulates interlaced with ultrafine fibers of less than $300 \mathrm{~nm}$ in diameter (Fig. 6a). The addition of a trace quantity of PEO $(0.1 \% \mathrm{w} / \mathrm{w})$ into the EC solution resulted in the formation of continuous ribbon-like fibers (Fig. 6b), attributable to the conductivity and surface tension lowering effective of PEO on the spin dope solution [40-43]. The incorporation of precursor compounds significantly reduced the diameter of EC-PEO fibers $(p<0.05)$, although the differences in diameter among the precursor-loaded samples were statistically insignificant $(p>0.05)$ (Table 1$)$. As illustrated by the frequency histograms in Fig. 6 , the incorporation of precursors reduced the variation in fiber diameter as compared to the EC-PEO nonwoven. Rodshaped and "chunky" features observed for higher SP loadings (100SP0HP and 75SP25HP in Fig. 6c and d, respectively) were likely the salicylic acid crystals produced due to oxidation of salicylaldehyde during the sample preparation process and/or the precipitation of SP when the precursor stock solution was added to the EC-PEO spinning dope. On the other hand, the electrospun fibers tended to fuse in samples with elevated HP contents (25SP75HP and
0SP100HP in Fig. $6 \mathrm{f}$ and g, respectively). Since HP was soluble in both ethanol and ethyl acetate, the incorporation of HP in the spin dope solution might have suppressed the vapor pressure of these solvents and hindered their evaporation during the electrospinning process, thereby resulting in wet materials collected on the substrate [50]. Overall, the SEM analysis indicated that the morphologies of EC-PEO electrospun nonwovens were dependent on the proportion of the SP and HP added in the spin dope solutions.

\subsection{Release profiles of hexanal and salicylaldehyde}

The simultaneous release profiles of hexanal and salicylaldehyde from 50SP50HP, after triggering with the acidified agarose gels, are presented on Figs. 7 and 8, respectively. For low $(0.003 \mathrm{M})$ and medium $(0.03 \mathrm{M})$ acid concentrations, an initial release lag was due to the rate-limiting hydration of the nonwoven and diffusion of acid into the fiber matrices. Following the lag phase, rapid releases of hexanal and salicylaldehyde were observed due to hydrolysis of the precursors on/near the surface of the electrospun fibers. The initial release rates of the aldehydes increased with increasing acid concentration, as expected, due to enhanced hydrolysis of the imidazolidine precursor.

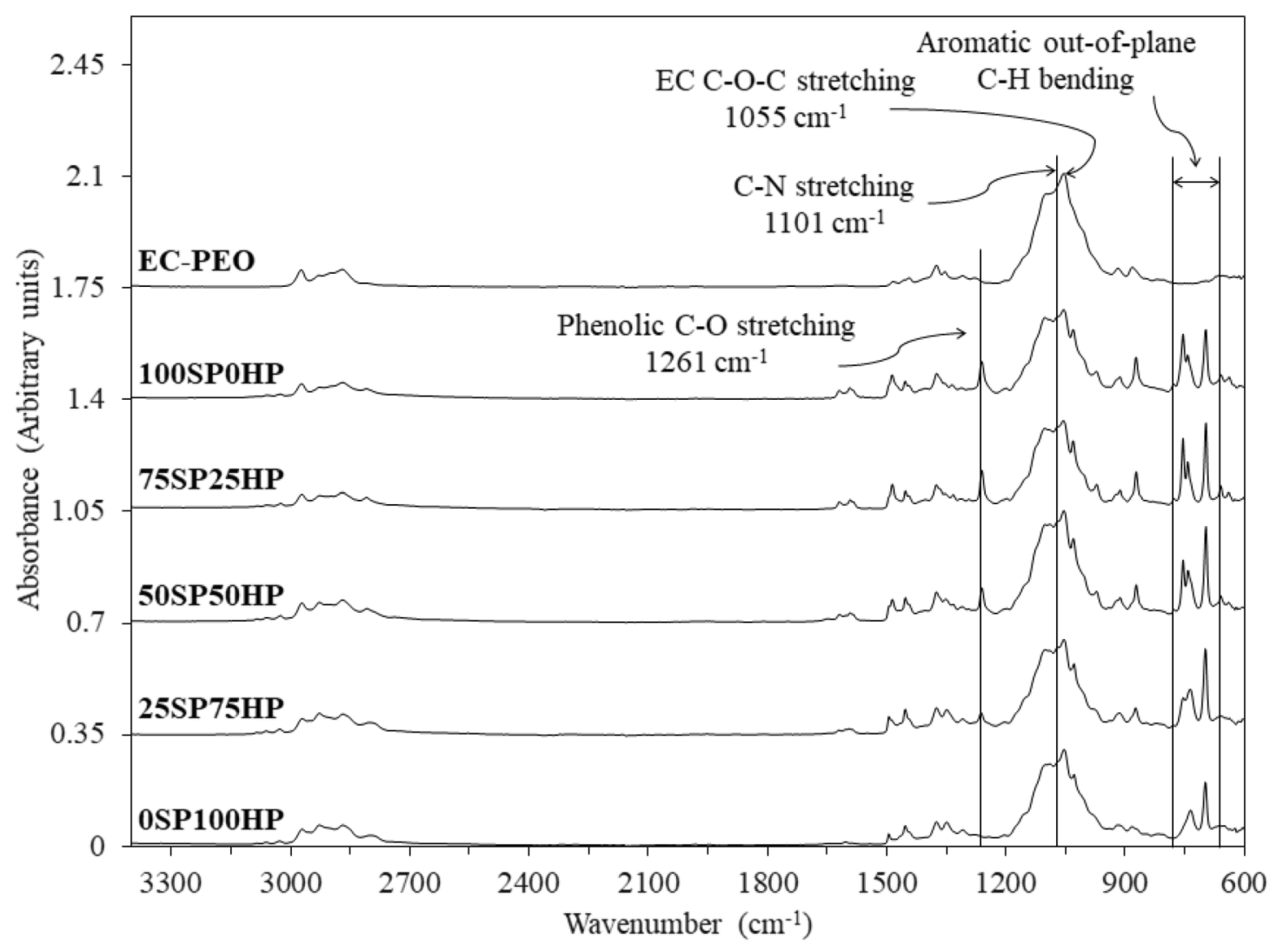

Fig. 5 Comparisons of ATR-FTIR spectra of pristine and precursor-loaded electrospun fibers 
(a)

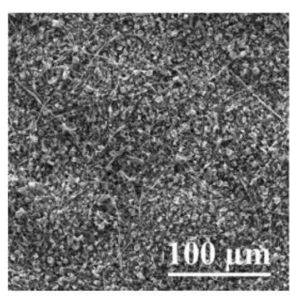

(b)

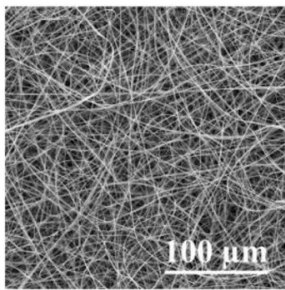

(c)

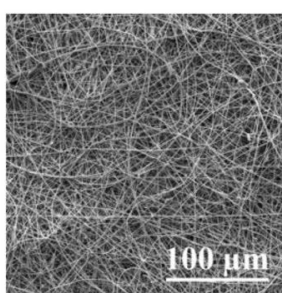

(d)

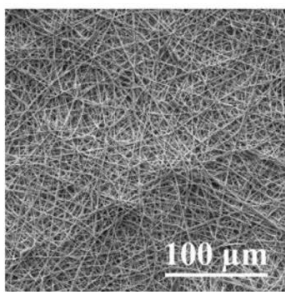

(e)

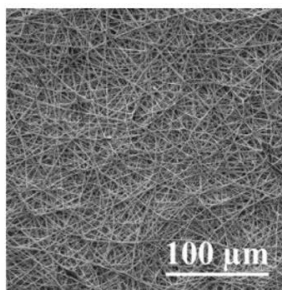

(f)

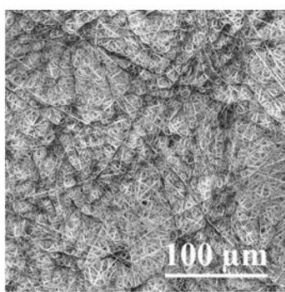

(g)
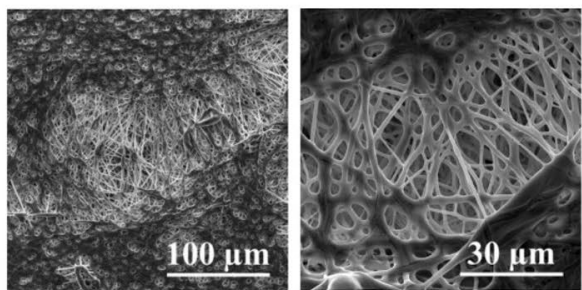

Fig. 6 SEM micrographs of electrospun fibers with and without the aldehyde precursors: a EC; b EC-PEO; c 100SPOHP; d 75SP25HP; e 50SP50HP; f 25SP75HP; and g 0SP100HP. Histograms show the fiber
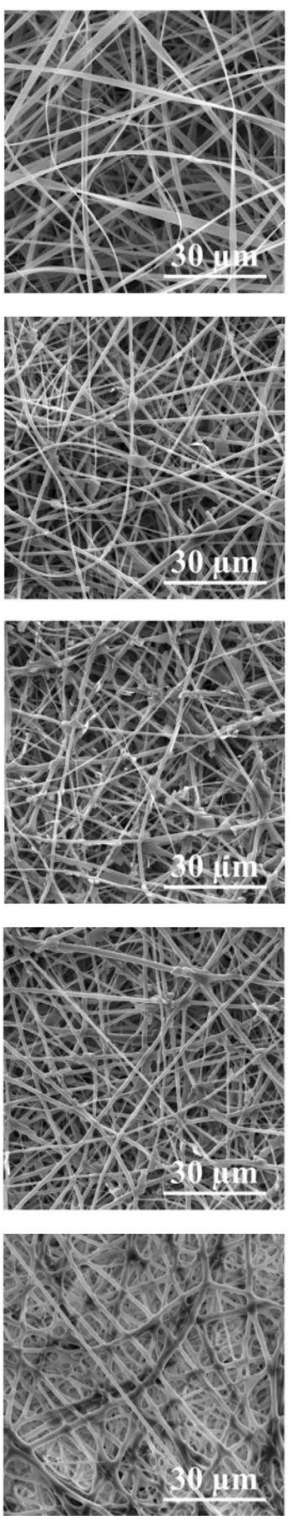
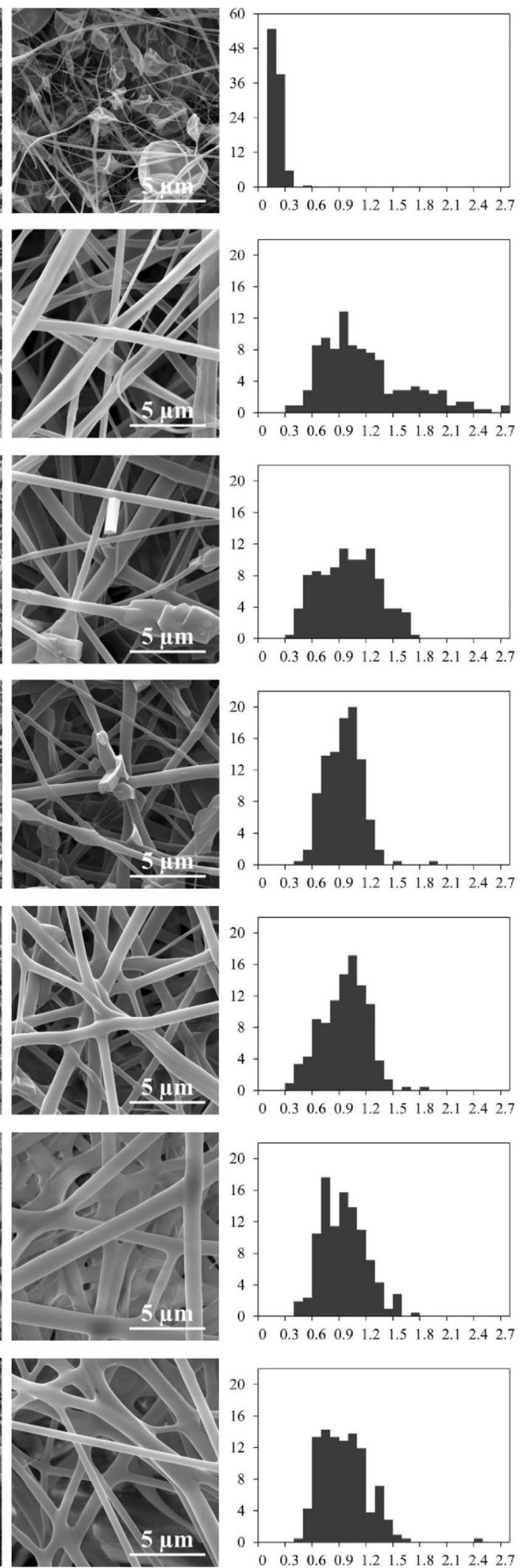

diameter distribution (y-axis; \% count) in various diameter intervals $(\mathrm{x}$-axis; $\mu \mathrm{m})$ 
Table 1 Mean fiber diameters and standard deviations of pristine EC and precursor-loaded EC-PEO electrospun fibers

\begin{tabular}{ll}
\hline Electrospun fibers & Fiber diameters, $\mu \mathrm{m}$ \\
\hline EC (no precursor) & $0.11 \pm 0.06^{\mathrm{a}}$ \\
EC-PEO (no precursor) & $1.09 \pm 0.52^{\mathrm{b}}$ \\
100SP0HP & $0.91 \pm 0.32^{\mathrm{c}}$ \\
75SP25HP & $0.84 \pm 0.20^{\mathrm{c}}$ \\
50SP50HP & $0.86 \pm 0.25^{\mathrm{c}}$ \\
25SP75HP & $0.85 \pm 0.24^{\mathrm{c}}$ \\
0SP100HP & $0.86 \pm 0.27^{\mathrm{c}}$ \\
\hline
\end{tabular}

Diameters are mean \pm standard deviation $(n=210)$. Values with different script letters represent statistically significant differences $(p<0.05)$. Detail one-way ANOVA and Tukey's HSD analyses are shown in Tables S1 and S2, respectively

The reduction in the rigidity of the agarose gel as the acid concentration increased might have also facilitated the diffusion of citric acid from the gel matrices to the precursorsloaded nonwoven [51]. While 0.003 and $0.03 \mathrm{M}$ citric acid agarose gels displayed diminishing hexanal release rates with time, an anomaly was observed for the agarose gel at $0.3 \mathrm{M}$ citric acid concentration; here, a decay in hexanal concentration was detected between 30 and $120 \mathrm{~min}$, followed by gradual recovery of hexanal concentration in the headspace. Similar behaviours were observed for salicylaIdehyde release, except that the decay of salicylaldehyde was detected at 0.03 and $0.3 \mathrm{M}$ acid concentrations (Fig. 8).

Aldehydes are known to self-react or react with other aldehyde molecules through acid-catalyzed aldol condensation, producing $\alpha, \beta$-unsaturated carbonyl products with the number of carbons equals to the sum of the carbon atoms present in the reactant aldehydes [52]. For example, hexanal can undergo self-aldol condensation to form 2-butyl-2-octenal under acidic conditions, or with other aliphatic aldehydes to give mixed aldol condensation products [53]. The anomalous release behaviours at elevated acid concentrations can be attributed to the mixed and self-aldol condensation of the hexanal and salicylaldehyde, catalyzed by the acidic condition. On the other hand, the recoveries of hexanal and salicylaldehyde concentrations in the headspace are attributable to partial neutralization of citric acid by the diamine regenerated during the hydrolysis reaction. Under the experimental condition, the highest concentrations of aldehydes accumulated in the headspace were observed when $0.03 \mathrm{M}$ citric acid was

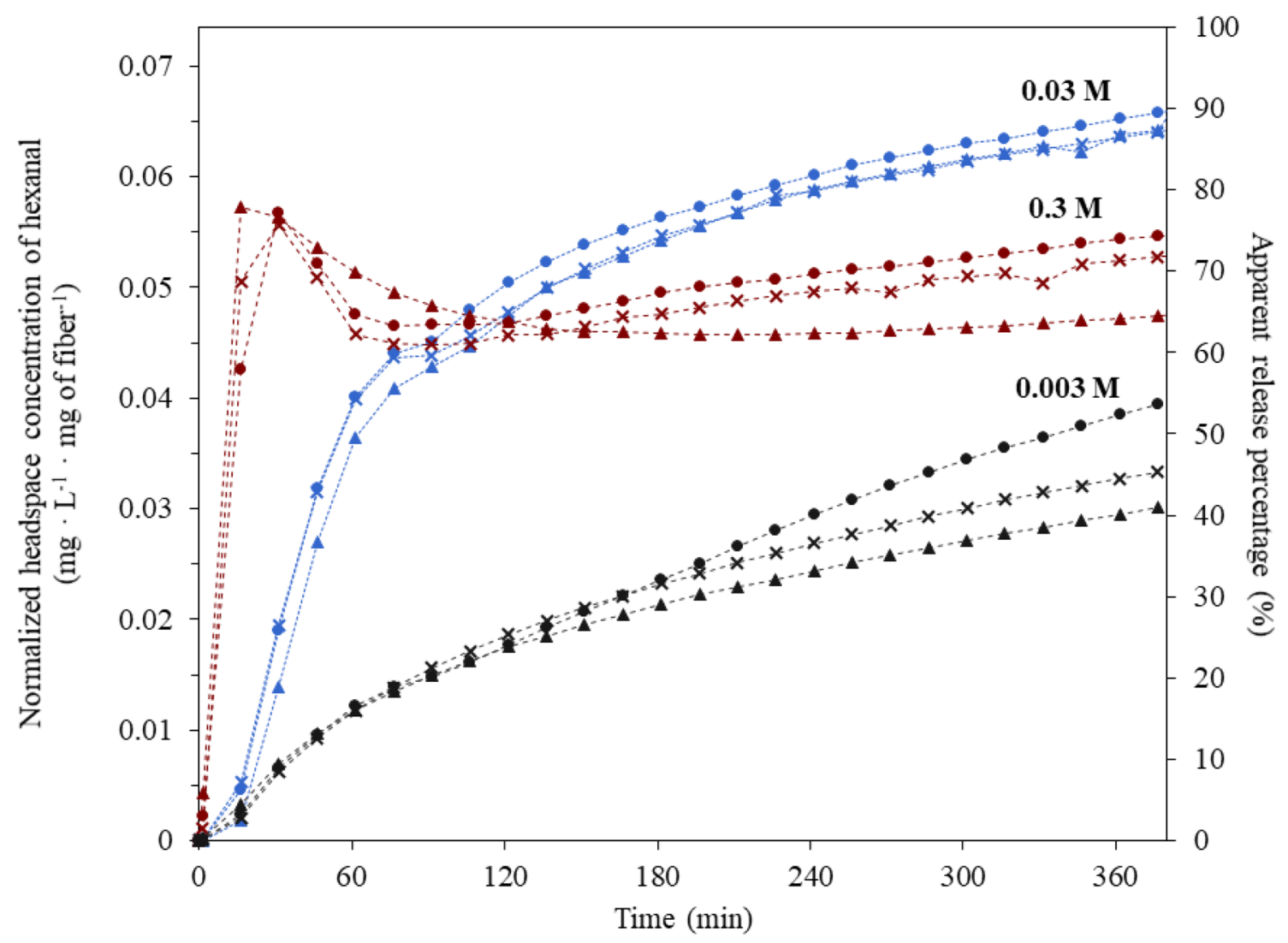

Fig. 7 Release profiles of hexanal from precursor-loaded 50SP50HP electrospun fibers, triggered by acidified agarose gels with three different concentrations $(0.003,0.03$, and $0.3 \mathrm{M})$ of citric acid $(n=3)$ 


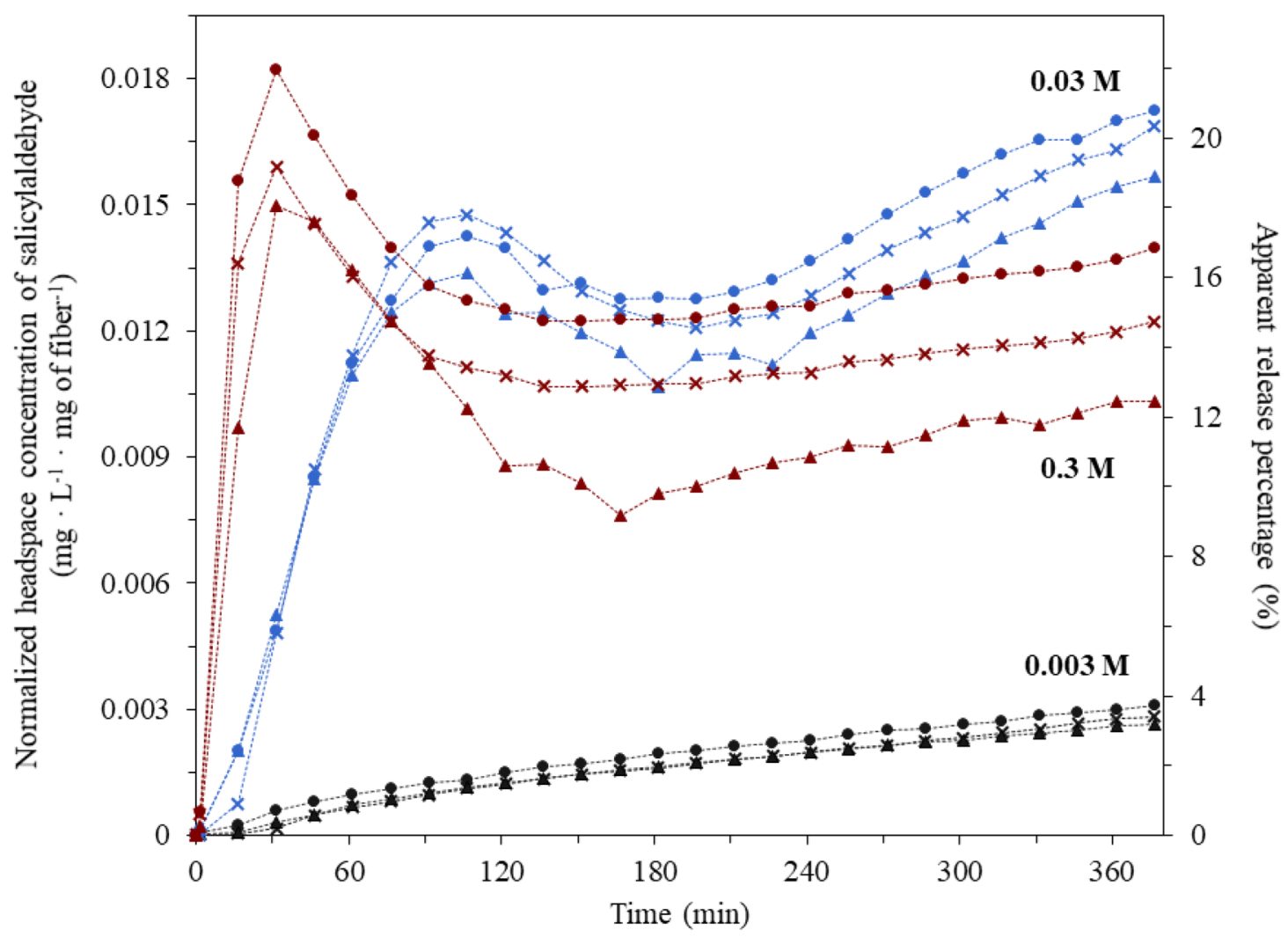

Fig. 8 Release profiles of salicylaldehyde from precursor-loaded 50SP50HP electrospun fibers, activated by acidic agarose gels with three different concentrations $(0.003,0.03$, and $0.3 \mathrm{M})$ of citric acid $(n=3)$

used, highlighting the importance of controlling the acid concentration for achieving an optimal aldehyde release profile. Overall, higher headspace concentrations were observed for hexanal than salicylaldehyde, indicative of higher hydrolysis rate of HP than SP. This observation also can be related to the higher vapor pressure of hexanal $\left(1507 \mathrm{~Pa}\right.$ at $\left.25^{\circ} \mathrm{C}\right)[54]$ than salicylaldehyde $\left(79 \mathrm{~Pa}\right.$ at $\left.25^{\circ} \mathrm{C}\right)$ [55], resulting in a higher partition of the former into the headspace air.

\section{Conclusions}

In this study, imidazolidine precursors for salicylaldehyde and hexanal were synthetized and encapsulated in electrospun EC-PEO nonwovens by free surface electrospinning. FTIR analyses did not reveal any specific interaction between EC-PEO and the precursors, suggesting that the latter were mainly physically entrapped in the fiber matrix. Morphologies of the electrospun fibers were strongly dependent on hexanal and salicylaldehyde precursors blend ratio; elevated HP proportion suppressed the evaporation of the solvent (ethanol-ethyl acetate blend), resulting in fused fibers. Simultaneous releases of hexanal and salicylaldehyde from the electrospun EC-PEO fibers were achieved by exposing the precursors-loaded nonwovens to an acidified agarose gel. While the initial release rates of the aldehydes increased with increasing acid concentration, anomalous trends were observed as time progressed, which were attributed to the competing precursor hydrolysis, aldol condensation of the aldehydes produced, and partial neutralization of the acid by the regenerated diamine. Further investigations on these reactions are needed to better understand the complex release kinetics of the encapsulated precursor system, in order to exploit hexanal and salicylaldehyde for active packaging applications involving real food products.

Acknowledgement The authors gratefully acknowledge the funding supports from Natural Sciences and Engineering Research Council of Canada (NSERC) and iFood Packaging Systems Corp.

\section{Compliance with ethical standards}

Conflicts of interests The authors declared that no conflicts of interests existed.

Open Access This article is licensed under a Creative Commons Attribution 4.0 International License, which permits use, sharing, 
adaptation, distribution and reproduction in any medium or format, as long as you give appropriate credit to the original author(s) and the source, provide a link to the Creative Commons licence, and indicate if changes were made. The images or other third party material in this article are included in the article's Creative Commons licence, unless indicated otherwise in a credit line to the material. If material is not included in the article's Creative Commons licence and your intended use is not permitted by statutory regulation or exceeds the permitted use, you will need to obtain permission directly from the copyright holder. To view a copy of this licence, visit http://creativeco mmons.org/licenses/by/4.0/.

\section{References}

1. FAO (2011) Global food losses and food waste-extent, causes and prevention. http://www.fao.org/docrep/014/mb060e/ mb060e00.pdf. Accessed 6 July 2018.

2. Plazzotta S, Manzocco L, Nicoli MC (2017) Fruit and vegetable waste management and the challenge of fresh-cut salad. Trends Food Sci Technol 63:51-59

3. Ramos B, Miller FA, Brandão TRS et al (2013) Fresh fruits and vegetables-an overview on applied methodologies to improve its quality and safety. Innov Food Sci Emerg Technol 20:1-15

4. Meireles A, Giaouris E, Simões M (2016) Alternative disinfection methods to chlorine for use in the fresh-cut industry. Food Res Int 82:71-85

5. Ma L, Zhang M, Bhandari B, Gao Z (2017) Trends in Food Science \&Technology Recent developments in novel shelf life extension technologies of fresh-cut fruits and vegetables. Trends Food Sci Technol 64:23-38

6. Rico D, Martín-Diana AB, Barat JM, Barry-Ryan C (2007) Extending and measuring the quality of fresh-cut fruit and vegetables: a review. Trends Food Sci Technol 18:373-386

7. Gopal A, Coventry J, Wan J et al (2010) Alternative disinfection techniques to extend the shelf life of minimally processed iceberg lettuce. Food Microbiol 27:210-219

8. Feliziani E, Lichter A, Smilanick JL, Ippolito A (2016) Disinfecting agents for controlling fruit and vegetable diseases after harvest. Postharvest Biol Technol 122:53-69

9. Sáenz-garza NE, Delaquis P, Durance T (2013) Microencapsulation of hexanal by radiant energy vacuum microwave-molecular inclusion for controlled release and inhibition of Penicillium expansum in a model system and on apple tissue. Food Res Int 52:496-502

10. Song J, Hildebrand PD, Fan L et al (2007) Effect of hexanal vapor on the growth of postharvest pathogens and fruit decay. J Food Sci 72:108-112

11. Lanciotti R, Belletti N, Patrignani F et al (2003) Application of hexanal, (E)-2-hexenal, and hexyl acetate to improve the safety of fresh-sliced apples. J Agric Food Chem 51:2958-2963

12. Jincy $M$, Djanaguiraman $M$, Jeyakumar $P$ et al (2017) Inhibition of phospholipase $D$ enzyme activity through hexanal leads to delayed mango (Mangifera indica L.) fruit ripening through changes in oxidants and antioxidant enzymes activity. Sci Hortic (Amsterdam) 218:316-325

13. Cheema A, Padmanabhan P, Amer A et al (2018) Postharvest hexanal vapor treatment delays ripening and enhances shelf life of greenhouse grown sweet bell pepper (Capsicum annum L.). Postharvest Biol Technol 136:80-89

14. Pak Dek MS, Padmanabhan P, Subramanian J, Paliyath G (2018) Inhibition of tomato fruit ripening by $1-\mathrm{MCP}$, wortmannin and hexanal is associated with a decrease in transcript levels of phospholipase $D$ and other ripening related genes. Postharvest Biol Technol 140:50-59
15. Sharma M, Jacob JK, Subramanian J, Paliyath G (2010) Hexanal and 1-MCP treatments for enhancing the shelf life and quality of sweet cherry (Prunus avium L.). Sci Hortic (Amsterdam) 125:239-247

16. Kumar SK, El Kayal W, Sullivan JA et al (2018) Pre-harvest application of hexanal formulation enhances shelf life and quality of 'Fantasia' nectarines by regulating membrane and cell wall catabolism-associated genes. Sci Hortic (Amsterdam) 229:117-124

17. Kreft S, Janěs D (2008) Salicylaldehyde is a characteristic aroma component of buckwheat groats. Food Chem 109:293-298

18. FDA (2018) Code of Federal Regulations Title 21. https://www. accessdata.fda.gov/scripts/cdrh/cfdocs/cfcfr/CFRSearch. $\mathrm{cfm} ? \mathrm{FR}=171.515$. Accessed 10 July 2018

19. Smid EJ, de Witte Y, Gorris LGM (1995) Secondary plant metabolites as control agents of postharvest Penicillium rot on tulip bulbs. Postharvest Biol Technol 6:303-312

20. Radulović N, Mišić M, Aleksić J et al (2007) Antimicrobial synergism and antagonism of salicylaldehyde in Filipendula vulgaris essential oil. Fitoterapia 78:565-570

21. Liu TT, Tseng YW, Yang TS (2016) Functionalities of conjugated compounds of $\gamma$-aminobutyric acid with salicylaldehyde or cinnamaldehyde. Food Chem 190:1102-1108

22. Koenning SR, Overstreet C, Noling JW et al (1999) Survey of crop losses in response to phytoparasitic nematodes in the United States for 1994. J Nematol 31:587-618

23. Caboni P, Aissani N, Cabras T et al (2013) Potent nematicidal activity of phthalaldehyde, salicylaldehyde, and cinnamic aldehyde against Meloidogyne incognita. J Agric Food Chem 61:1794-1803

24. Almenar E, Auras R, Rubino M, Harte B (2007) A new technique to prevent the main post harvest diseases in berries during storage: Inclusion complexes $\beta$-cyclodextrin-hexanal. Int J Food Microbiol 118:164-172

25. Jash A, Lim L-T (2018) Triggered release of hexanal from an imidazolidine precursor encapsulated in poly(lactic acid) and ethylcellulose carriers. J Mater Sci 53:2221-2235

26. Jash A, Paliyath G, Lim L-T (2018) Activated release of bioactive aldehydes from their precursors embedded in electrospun poly (lactic acid) nonwovens. RCS Adv 2018:19930-19938

27. Lim L-T, Mendes AC, Chronakis IS (2019) Electrospinning and electrospraying technologies for food applications. Adv Food Nutr Res 88:167-234

28. Xiao Q, Lim L-T (2018) Pullulan-alginate fibers produced using free surface electrospinning. Int J Biol Macromol 112:809-817

29. Moreira JB, Lim L-T, da Zavareze ER et al (2019) Antioxidant ultrafine fibers developed with microalga compounds using a free surface electrospinning. Food Hydrocoll 93:131-136

30. Ranjan S, Chandrasekaran R, Paliyath G et al (2020) Effect of hexanal loaded electrospun fiber in fruit packaging to enhance the post harvest quality of peach. Food Packag Shelf Life 23:100447

31. Kostakova E, Meszaros L, Gregr J (2009) Composite nanofibers produced by modified needleless electrospinning. Mater Lett 63:2419-2422

32. Dosunmu OO, Chase GG, Kataphinan W, Reneker DH (2006) Electrospinning of polymer nanofibres from multiple jets on a porous tubular surface. Nanotechnology 17:1123-1127

33. Fang $Y, X u L$ (2019) Four self-made free surface electrospinning devices for high-throughput preparation of high-quality nanofibers. Beilstein J Nanotechnol 10:2261-2274

34. Ahmed A, Yin J, Xu L, Khan F (2020) High-throughput free surface electrospinning using solution reservoirs with different radii and its preparation mechanism study. J Mater Res Technol 9:9059-9072 
35. Li H, Liu K, Sang Q et al (2017) A thermosensitive drug delivery system prepared by blend electrospinning. Colloids Surfaces B Biointerfaces 159:277-283

36. Liu Y, Deng L, Zhang C et al (2018) Comparison of ethyl cellulose-gelatin composite films fabricated by electrospinning versus solvent casting. J Appl Polym Sci 135:1-10

37. Ahenkorah CK, Zaitoon A, Apalangya VA et al (2020) Moistureactivated release of hexanal from imidazolidine precursor encapsulated in ethylcellulose/poly(ethylene oxide) nonwoven for shelf-life extension of papaya. Food Packag Shelf Life 25:100532

38. Niu B, Zhan L, Shao P et al (2020) Electrospinning of zein-ethyl cellulose hybrid nanofibers with improved water resistance for food preservation. Int J Biol Macromol 142:592-599

39. Lu JW, Zhu YL, Guo ZX et al (2006) Electrospinning of sodium alginate with poly(ethylene oxide). Polymer 47:8026-8031

40. Nie H, He A, Wu W et al (2009) Effect of poly(ethylene oxide) with different molecular weights on the electrospinnability of sodium alginate. Polymer (Guildf) 50:4926-4934

41. Alborzi S, Lim L-T, Kakuda Y (2010) Electrospinning of sodium alginate-pectin ultrafine fibers. J Food Sci 75:c100-c107

42. Vega-Lugo AC, Lim L-T (2012) Effects of poly(ethylene oxide) and $\mathrm{pH}$ on the electrospinning of whey protein isolate. J Polym Sci Part B Polym Phys 50:1188-1197

43. Zaitoon A, Lim L-T (2020) Effect of poly(ethylene oxide) on the electrospinning behavior and characteristics of ethyl cellulose composite fibers. Materialia 10:100649

44. Dai R, Lim L-T (2015) Release of allyl isothiocyanate from mustard seed meal powder entrapped in electrospun PLA-PEO nonwovens. Food Res Int 77:467-475

45. Vega-Lugo AC, Lim L-T (2009) Controlled release of allyl isothiocyanate using soy protein and poly(lactic acid) electrospun fibers. Food Res Int 42:933-940

46. Morinaga $H$, Morikawa $H$, Sudo A, Endo $T$ (2010) A new watersoluble branched poly(ethylene imine) derivative having hydrolysable imidazolidine moieties and its application to long-lasting release of aldehyde. J Polym Sci Part A Polym Chem 48:4529-4536

47. Buchs(née Levrand) B, Godin G, Trachsel A et al (2011) Reversible aminal formation: controlling the evaporation of bioactive volatiles by dynamic combinatorial/covalent chemistry. European J Org Chem, pp 681-695.

48. Silverstein RM, Webster FX, Kiemle DJ (2005) Spectrometric identification of organic compounds, 7th edn. Wiley, New Jersey

49. Chauhan K, Kaur J, Kumari A et al (2015) Efficient method of starch functionalization to bis-quaternary structure unit. Int J Biol Macromol 80:498-505

50. Moomand K, Lim L-T (2015) Effects of solvent and n-3 rich fish oil on physicochemical properties of electrospun zein fibres. Food Hydrocoll 46:191-200

51. Chirapart A, Ohno M, Ukeda H et al (1997) Effects of partial acid hydrolysis on physical and chemical properties of agar from a newly reported Japanese agarophyte (Gracilariopsis lemaneiformis). J Appl Phycol 9:73-76

52. Casale MT, Richman AR, Elrod MJ et al (2007) Kinetics of acidcatalyzed aldol condensation reactions of aliphatic aldehydes. Atmos Environ 41:6212-6224

53. Abreu I, Da Costa NC, van Es A et al (2017) Natural occurrence of aldol condensation products in Valencia orange oil. J Food Sci 82:2805-2815

54. Daubert TE, Danner RP (1989) Physical and thermodynamic properties of pure chemicals data compilation. Taylor and Francis, UK.

55. National Center for Biotechnology Information (2021) PubChem Compound Summary for CID 6998, Salicylaldehyde. https ://pubchem.ncbi.nlm.nih.gov/compound/Salicylaldehyde Accessed 13 January 2021.

Publisher's Note Springer Nature remains neutral with regard to jurisdictional claims in published maps and institutional affiliations. 